\title{
The role of passion in sustainable psychological well-being
}

Robert J Vallerand

Correspondence: vallerand robert_J@uqam.ca

Laboratore de Recherche sur le Comportement Social Université du Québec à Montréal, Canada

\begin{abstract}
Using the Dualistic Model of Passion (DMP), the purpose of the present paper is to show the role of passion for activities in sustainable psychological well-being. Passion is defined as a strong inclination toward a self-defining activity that people like (or even love), find important, and in which they invest time and energy on a regular basis. The model proposes the existence of two types of passion: harmonious and obsessive. Harmonious passion originates from an autonomous internalization of the activity into one's identity while obsessive passion emanates from a controlled internalization and comes to control the person. Through the experience of positive emotions during activity engagement that takes place on a regular and repeated basis, it is posited that harmonious passion contributes to sustained psychological well-being while preventing the experience of negative affect, psychological conflict, and ill-being. Obsessive passion is not expected to produce such positive effects and may even facilitate negative affect, conflict with other life activities, and psychological ill-being. Research supporting the proposed effects and processes is presented and directions for future research are proposed.
\end{abstract}

Psychological well-being, broadly defined as happiness, life satisfaction, and self-growth, represents one of the most important aspects of efficient psychological functioning. Indeed, much research reveals that happy people experience a number of benefits ranging from physical health to better relationships to high-level performance (e.g., Huppert 2009; Lyubomirsky et al. 2005). Often overlooked is the fact that psychological well-being is not the absence of ill-being (Diener 2000; Keyes 2007). Just as not being poor is not tantamount to being rich, not experiencing any psychological problems is not equivalent to being psychologically flourishing (Huppert 2009; Seligman 2011). An important correlate of the above is that the determinants of psychological well-being should differ from those of ill-being (see Gable \& Haidt 2005; Garland et al. 2010; Keyes 2007). For instance, the absence of psychological stressors does not ensure thriving in one's life. It merely reduces the likelihood of suffering.

In recent years, some authors (e.g., Lyubomirsky et al. 2005) have suggested that engaging in "happiness-relevant activities" (especially intentional activities) represents one way to facilitate psychological well-being. I agree with this position and further posit that having a passion for an activity represents an important type of high involvement in activities that may lead to sustainable positive effects on psychological well-being. Indeed, because people who have a passion for a given activity typically engage in this

(c) 2012 Vallerand; licensee Springer. This is an Open Access article distributed under the terms of the Creative Commons Attribution License (http://creativecommons.org/licenses/by/2.0), which permits unrestricted use, distribution, and reproduction in any medium, provided the original work is properly cited. 
activity several hours each week, they may be experiencing positive affective experiences that should facilitate well-being. However, not all intentional activites facilitate psychological well-being. As will be described below, two types of passion exist. Although one type called harmonious passion is expected to facilitate sustainable psychological wellbeing through the repeated experience of positive emotions during task engagement, a second type of passion, called obsessive, is not expected to produce such effects and may even arouse negative emotions and interfere with leading a balanced, happy life.

The purpose of this paper is to show how passion, and especially harmonious passion, plays a critical role in sustainable psychological well-being. The paper focuses exclusively on the passion-well-being relationship. The reader interested in other outcomes is referred to Vallerand (2010) for a review. In the first two sections, I present the Dualistic Model of Passion (DMP; Vallerand 2008, 2010; Vallerand et al. 2003) and research supporting the validity of the passion concept. Then, a review is provided of the studies on the role of passion in psychological well-being, including research on the mechanisms through which passion is hypothesized to contribute to sustainable psychological well-being. Finally, I conclude with suggestions for future research.

\section{On the Psychology of Passion The Concept of Passion}

Passion has generated a lot of attention from philosophers. Their focus, however, was more on the emotional aspect of passion than on its motivational dimension as is the case with the present approach on passion. Two perspectives have emerged (see Rony 1990). The first posits that passion entails a loss of reason and control as exemplified in the writings of Plato (429-347 BC) and Spinoza (1632-1677). In line with the etymology of the word passion (from the latin "passio" for suffering) people afflicted with passion are seen as experiencing a kind of suffering, as if they were slaves to their passion, because it comes to control them. The second perspective portrays passion in a more positive light. For instance, Descartes (1596-1650) sees passions as strong emotions with inherent behavioral tendencies that can be positive as long as reason underlies the behavior. Finally, Hegel (1770-1831) argues that passions are necessary to reach the highest levels of achievement. Thus, this second view portrays passion in a more positive light as some favorable outcomes may be experienced when individuals are in control of their passion.

Very little has been written on the psychology of passion for activities until recently. The few psychologists who have looked at the concept have underscored its motivational aspect. For instance, some authors have proposed that people will spend large amounts of time and effort in order to reach their passionate goals (see Frijda et al. 1991) or working on the activity that they love (Baum \& Locke 2004). Nearly all empirical work on passion has been conducted in the area of close relationships under the rubric of passionate love (e.g., Hatfield \& Walster 1978). Although such research is important, it does not deal with the main topic at hand, namely passion toward activities. Finally, while several theories have been proposed wherein loving an activity is hypothesized to lead to some positive benefits, no psychological theory makes the case that your love for a given activity can have either adaptive or deleterious effects on your life; that something you love can be "good" or "bad" for you (see Vallerand 2010 
for conceptual comparisons between passion and these other concepts). The duality of passion needs to be accounted for.

\section{The Dualistic Model of Passion (DMP)}

Vallerand and his colleagues (Vallerand 2008, 2010,; Vallerand et al. 2003; Vallerand \& Houlfort 2003) have recently developed a model of passion that addresses the dualism inherent in passion. In line with Self-Determination Theory (Deci \& Ryan 2000), the DMP posits that individuals are motivated to explore their environment in order to grow as individuals. In so doing, they engage in a variety of activities. Of these, only a few will be perceived as particularly enjoyable, important, and to have some resonance with how people see themselves. From these few activities one or two will eventually be preferred and engaged in on a regular basis and turn out to be passionate. Thus, Vallerand et al. (2003) define passion as a strong inclination toward a self-defining activity that one likes (or even loves), finds important, and in which one invests time and energy on a regular basis. The issue of identity is important. In fact, passionate activities come to be so self-defining that they represent central features of one's identity. For instance, those who have a passion for playing basketball or songwriting do not merely engage in these activities. They see themselves as "basketball players" or "songwriters". In sum, a passionate activity is not simply an activity that one loves dearly, values highly, and engages in on a regular basis. It is also something that comes to define oneself. The activity becomes an inherent part of who the person is.

Much theory and research reveals that elements from the environment can be internalized in identity (e.g., Aron et al. 1992; Deci \& Ryan 2000). This is because there is an organismic integration process that entails that the self becomes more complex over time through the internalization of elements from the environment as well as the interrelations of self constituents (Deci \& Ryan 2000). At some point, representations of activities that people enjoy and engage in on a regular basis will be incorporated in the person's identity to the extent that they are highly valued (Aron et al. 1992; Csikszentmihalyi et al. 1993), thereby leading to passions toward these activities.

Furthermore, Self-determination theory and research has shown that elements from the environment can be internalized in either a controlled or an autonomous fashion (see Deci et al. 1994; Sheldon 2002; Vallerand et al. 1997). Thus, in line with the above, the DMP proposes that there are two types of passion, obsessive and harmonious, that can be distinguished in terms of how the passionate activity has been internalized into one's identity.

Obsessive passion results from a controlled internalization of the activity into one's identity and self. A controlled internalization originates from intra and/or interpersonal pressure typically because certain contingencies are attached to the activity such as feelings of social acceptance or self-esteem (see Mageau et al. in press), or because the sense of excitement derived from activity engagement is uncontrollable. People with an obsessive passion can thus find themselves in the position of experiencing an uncontrollable urge to partake in the activity they view as important and enjoyable. The passion for the activity comes to control the person. They cannot help but to engage in the passionate activity leading to rigid persistence toward the activity. While such rigid persistence may at times lead to some benefits (e.g., improvement on the activity over time), it may also incur some costs, potentially leading to less than optimal functioning within the confines 
of the passionate activity because of the lack of flexibility that it entails. Such a rigid and defensive style should lead to self-closure from intrapersonal and interpersonal experiences (Aron 1992), to a poor integrative experience during task engagement (Hodgins \& Knee 2002), and thus to negative emotional experiences, while reducing the positive affective outcomes that would normally be experienced (Hodgins \& Knee 2002). Furthermore, such a rigid persistence may lead to the experience of conflict with other aspects of the person's life when engaging in the passionate activity (when one should be doing something else, for instance), as well as to frustration and rumination about the activity when prevented from engaging in it because of the lost opportunity.

Conversely, harmonious passion results from an autonomous internalization of the activity representation into the person's identity. An autonomous internalization occurs when individuals have freely accepted the activity as important for them without any or little contingencies attached to it. This type of internalization emanates from the intrinsic and integrative tendencies of the self (Deci \& Ryan 2000; Ryan \& Deci 2003). It produces a motivational force to engage in the activity willingly and engenders a sense of volition and personal endorsement about pursuing the activity. When harmonious passion is at play, individuals do not experience an uncontrollable urge to engage in the passionate activity, but rather freely choose to do so. With this type of passion, the activity occupies a significant but not overpowering space in the person's identity and is in harmony with other aspects of the person's life. In other words, with harmonious passion the authentic integrating self (Deci \& Ryan 2000) is at play allowing the person to fully partake in the passionate activity with a flexibility and a mindful (Brown et al. 2007) open manner that is conducive to positive experiences (Hodgins \& Knee 2002).

Consequently, people with a harmonious passion should be able to fully focus on the task at hand and experience positive outcomes both during (e.g., flow, positive affect, concentration) and after task engagement (e.g., satisfaction, general positive affect). Thus, there should be little or no conflict between the person's passionate activity and his/her other life activities. Furthermore, when prevented from engaging in their passionate activity, people with a harmonious passion should be able to adapt well to the situation and focus their attention and energy on other tasks that need to be done. Finally, with harmonious passion, the person is in control of the activity and can decide when to and when not to engage in the activity. People with a harmonious passion are able to decide not to engage in the activity on a given day if needed or even to eventually terminate the relationship with the activity if they decide it has become a permanent negative factor in their life. Thus, behavioral engagement in the passionate activity can be seen as flexible.

\section{Initial Research on the Concept of Passion}

There were three major purposes to the initial work on passion (Vallerand et al. 2003): to determine the prevalence of passion for an activity in one's life, to develop the Passion Scale, and to test the validity of some of the elements of the passion constructs. Thus, Vallerand et al. (2003, Study 1) had over 500 university students complete the Passion Scale with respect to an activity that they loved, that they valued, and in which they invested time and energy (i.e., the passion definition), as well as other scales to test predictions derived from the DMP. A large variety of passionate activities were reported 
ranging from physical activity and sports to watching movies, playing a musical instrument, and reading. Participants reported engaging in their passionate activity for an average of 8.5 hours per week and had been engaging in that activity for almost six years. Thus, clearly passionate activities are meaningful to people and are long-lasting in nature. Furthermore, $84 \%$ of participants indicated that they had at least a moderate level of passion for a given activity in their lives (they scored at least four out of seven on a question asking them if their favorite activity was a " passion » for them). Second, as pertains to the development of the Passion Scale, results of exploratory and confirmatory factor analyses supported the presence of two factors corresponding to the two types of passion. These findings on the factor validity of the Passion Scale have been replicated in a number of studies in a variety of activities (e.g., Carbonneau et al. 2008; Castelda et al. 2007; Rousseau et al. 2002; Vallerand \& Houlfort 2003; Vallerand et al. 2006, Studies 1, 2, and 3). The Passion Scale consists of two subscales of six items each reflecting Obsessive (e.g., "I almost have an obsessive feeling toward this activity") and Harmonious Passion (e.g., "This activity is in harmony with other activities in my life"). Furthermore, internal consistency analyses have shown that both subscales are reliable (typically .75 and above). Finally, test-retest correlations over periods ranging from four to six weeks revealed moderately high stability values (in the .80 s, Rousseau et al. 2002), thereby supporting the factorial validity and reliability of the scale.

Finally, with respect to the third purpose, a series of critical findings pertained to the results from partial correlations (controlling for the correlation between the two types of passion) which showed that both harmonious and obsessive passions are positively associated with the passion criteria (loving the activity, valuing it, spending regular time and energy in it, and feeling that it is part of one's identity), thereby providing support for the definition of passion. In addition, both types of passion were found to relate to one's identity and only obsessive passion was found to significantly relate to a measure of conflict with other life activities. Thus, overall, these findings support the view that both harmonious and obsessive passions are indeed a "passion" as each one reflects the definition of the passion construct. Finally, other studies in this initial research (Vallerand et al. 2003) have also shown that obsessive (but not harmonious) passion correlated to rigid persistence in ill-advised activities such as cycling over ice and snow in winter (Vallerand et al. 2003, Study 3) and pursuing one's engagement in activities that have become negative for the person such as pathological gambling (Vallerand et al. 2003, Study 4).

In sum, initial research provided support for the concept of harmonious and obsessive passion. Since the initial publication, over 100 studies have been conducted on the concept of passion and have focused on a host of cognitive, affective, behavioral, relational, and performance outcomes experienced within the realms of hundreds of activities conducted in both our own as well as other laboratories. In general, such research reveals that harmonious passion predicts more adaptive outcomes than obsessive passion. In the present paper, I focus exclusively on research on the role of passion in psychological well-being (see Vallerand 2010, for research on other types of outcomes).

\section{Passion and Psychological Well-Being}

Theory and research have identified two facets of well-being (Ryan \& Deci, 2001). The first facet of well-being can be defined as the person's general happiness with his/her life (hedonic well-being: Diener, Emmons, Larsen, \& Griffin, 1998), while the second 
one is concerned with self-realization or personal growth (eudaimonic well-being: Ryff \& Keyes 1995). These different facets of well-being are posited to be related (e.g., one may be happy when reaching self-realization), but also to constitute separate factors of psychological well-being (e.g., one may be suffering while trying to reach one's potential see Miquelon \& Vallerand 2006). In the present paper, I refer to both types of well-being without distinction. As will be seen below, this is because passion, and especially harmonious passion, can positively contribute to both.

Of interest is the fact that not much attention has been given to how psychological well-being can be increased, let alone maintained following increases. There are several reasons for this (see Seligman 2011), including the fact that research reveals that there seems to be a psychological well-being set point for each individual determined by hereditary causes (e.g., Lykken \& Tellegen 1996). Furthermore, should there be some gains in well-being, these are expected to be momentary as people apparently adapt to change (e.g., the hedonic treadmill; Brickman \& Campbell 1971).

Although it is undoubtedly true that there is probably a hereditary set point with respect to psychological well-being and that people may habituate to events and circumstances, this does not mean that increases in psychological well-being are not possible or that such increases cannot be sustained over time. Indeed, some authors (e.g., Lyubomirsky et al. 2005; Seligman 2011) have suggested that engaging in certain activities may lead people to experience positive benefits as pertains to their well-being. Lyubomirski et al., in particular, posit that a certain class of activities they label "happiness-relevant activities" may actually lead to sustainable positive gains in well-being. What characterizes these activities is that they are intentional in nature and are deployed with effort. Examples are activities such as expressing gratitude (Algoe 2008), counting your blessings (Froh et al. 2008), and writing about life goals (King 2001) that have indeed been found to have positive effects on one's well-being. In addition, activities that reflect a person-activity fit, that allow people to reach goal-attainment, and that leave room for variety would appear important (Sheldon 2002). Based on these findings, Lyubomirsky and colleagues recommend that people "find new activities to become engaged in, preferably activities that fit their values and interests. They should make a habit out of initiating the activity while at the same time varying their focus and timing in terms of the way they implement the activity" (p. 126).

The position of Lyubomirsky and colleagues is refreshing and important. Their work opens up an avenue of research and interventions that could have drastic implications for the understanding of processes involved in facilitating the experience of sustainable psychological well-being. I agree with several of their suggestions. For instance, engaging in "intentional" activities has the potential to yield some important psychological benefits to the individual and in fact, better than circumstances that simply happen to people. Furthermore, psychological benefits are more likely to happen if such activities are in line with one's interests and values. However, my perspective differs from theirs on a number of points. First, I do not believe that it is necessary that an activity be new (or engaged in under new and varied conditions) to lead to some sustainable positive effects. I submit that a passionate activity that people have been engaging in for years (and sometimes a lifetime; Rousseau \& Vallerand 2003) under similar conditions may just do as well and maybe better. This is because when passionate about a given activity, people become "expert" in this activity, they grow psychologically as individuals, and their self 
in this sphere of activity becomes increasingly complex. Consequently, the same activity can offer opportunities for some renewable elements that will sustain the increases in psychological well-being. I even propose that if the activity is not passionate it may even be discarded along the way, especially if it is too demanding (e.g., exercise, especially initially). This will not be the case when people are passionate about an activity.

Second, even intentional activities in line with one's interests and values do not guarantee that activity engagement will be profitable to the person psychologically. As passion research reveals (see Vallerand 2008, 2010, for reviews), obsessive passion which is oriented toward a fun activity consonant with one's interests and values, nevertheless leads to less adaptive outcomes than harmonious passion and at times to clearly maladaptive consequences. This is because the quality of activity engagement associated with obsessive passion is not fully self-determined in nature. This is so because somewhere along the way some contingencies between the self and the activity have been developed (see Mageau et al. in press). Thus, not all intentional activities in line with one's interests and values lead to positive psychological effects. I posit that it is a harmonious passion for a given activity that will lead to the positive effects on psychological well-being and not obsessive passion.

Third, Lyubomirsky and colleagues never completely state the nature of the processes at play in their model. They repeatedly mention that self-concordant goals that are attained preferably in new activities will lead to positive effects on one's well-being. But not much else is mentioned regarding what it is that leads to the positive effects on well-being. What I suggest (and elaborate on in a later section) is that in line with Fredrickson (e.g., 2001), positive emotions and associated processes represent the important mechanisms that facilitate the positive effects of harmonious passion on well-being. This is because positive emotions lead one to expand the self and to broaden one's repertoire of skills (Fredrickson 2001). Positive emotions could explain why Lyubomirsky and their colleagues find that new activities and those where there is goal attainment to have positive effects on one's psychological well-being as such emotions are likely to be experienced under these conditions.

Thus, the thesis advanced here is the following. Because harmonious passion leads the person to experience positive emotions during activity engagement that, in turn, facilitate increases in psychological well-being, and because harmonious passion leads to activity engagement and thus to the experience of positive emotions on a regular basis (roughly 8 hours per week), it is posited that harmonious passion leads to increases in psychological well-being that are sustainable. Thus, passion for the activity is important because it is the motivational force that leads the person to engage in the activity on a regular basis. Further, the type of effects that will be experienced on a regular basis depends on the type of passion one has for such an activity. It is proposed that to the extent that one's passion is harmonious, then this will set in motion two positive functions: promoting psychological well-being and preventing the occurrence of ill being. However, if one's passion is obsessive, then the positive effects may not be forthcoming on psychological well-being and an increase in ill-being may even take place. I elaborate on the empirical support for the proposed effects and processes in later sections.

\section{Is Passion for an Activity Related to Psychological Well-Being?}

Our initial research sought to determine if there was a link between passion for an activity and psychological well-being. It involved senior citizens (Rousseau \& Vallerand 2003). We 
included measures of both psychological well-being such as life satisfaction (Diener et al. 1985), meaning in life (Steger et al. 2006), and vitality (Ryan \& Frederick 1997), as well as psychological ill-being (scales of anxiety and depression from the General Health Questionnaire of Goldberg \& Hillier 1979). In line with the above hypotheses, having a harmonious passion for an activity was expected to promote psychological well-being, while being obsessively passionate or non passionate was not. Furthermore, it was also hypothesized that harmonious passion should protect against ill-being because of the positive affective states it facilitates. Research supported these hypotheses. For instance, in this particular study, we found that harmonious passion toward one's favorite activity (e.g., playing cards, playing a musical instrument) positively predicted positive indices of psychological well-being but negatively predicted indices of ill-being. Conversely, obsessive passion positively predicted anxiety and depression, was negatively related to life satisfaction, and was unrelated to vitality and meaning in life. Thus, the promoting and protective functions of harmonious passion were supported while the less than optimal role of obsessive passion was demonstrated.

Subsequent research with young adults and teenagers has yielded similar findings. Specifically, harmonious passion toward activities such as sports, dramatic arts, work, and specialized areas of education was found to be positively related to life satisfaction and vitality (Houlfort et al 2011, Studies 1 and 2; Vallerand et al. 2008, Study 2), whereas obsessive passion for the same activities was either negatively related (Houlfort et al. 2011; Vallerand et al. 2007, Study 2) or unrelated (Vallerand et al. 2007, Study 1; Vallerand et al. 2008, Study 2) to these indices. It thus appears that harmonious (but not obsessive passion) contributes to psychological well-being in both younger and older populations using a number of measures, providing some support for the major hypothesis regarding the promotion of psychological well-being and the prevention of ill-being.

In the research discussed above, the focus was on people who were all passionate for a given activity and how such passion relates to psychological well-being (and illbeing). Such research, however, only compared passionate people between them and did not include non passionate people. Thus, it is not clear whether harmonious passion actually gives people a psychological boost and obsessive passion a drop in wellbeing relative to non passionate people. In a first study (Philippe, Vallerand, \& Lavigne, 2009, Study 1), over 750 men and women aged between 18 and 90 years completed a questionnaire containing the Passion Scale as well as assessing the passion criteria (i.e., loving and valuing the activity, spending regular time on the activity, and the activity being perceived as a "passion") with respect to an activity that was dear to their heart. Participants also completed scales assessing hedonic (life satisfaction; Diener et al. 1985 ) and eudaimonic (self-realization; Ryff \& Keyes 1995) well-being. Using the passion criteria discussed previously, we distinguished those individuals who were highly passionate (a mean of 5 and more on a 7-pt scale on the 4 passion criteria) from those who were not (below a mean of 5 on the passion criteria). Furthermore, in line with Vallerand and Houlfort (2003), among the passionate individuals, we distinguished those who were "harmoniously-passionate" (those with a higher z-score on the harmonious passion than on the obsessive passion subscale) from those who were "obsessively-passionate" (those with a higher z-score on the obsessive than on the 
harmonious passion subscale). We then compared the three groups on the two types of psychological well-being indices.

The results showed that being harmoniously passionate for a given activity leads to higher levels of psychological well-being on both hedonic and eudaimonic well-being relative to being obsessively passionate and non-passionate (see Figure 1). These findings thus replicated the findings of the research reviewed above on the positive role of harmonious passion in psychological well-being. Of interest in the present research is the fact that these findings were obtained with men and women of various ages across the lifespan. Another finding of importance is that non passionate and obsessively-passionate individuals did not differ. This result is interesting as it raises the question of the role of obsessive passion in well-being. Specifically, is it simply that obsessive passion does not lead to positive or negative effects (relative to being non passionate) or is it that both obsessive passion and not being passionate have similar deleterious effects on psychological well-being?

To address the above issues, Philippe et al. (2009, Study 2) had different participants from Study 1 (again across the lifespan) complete the Passion Scale and a scale of eudaimonic well-being (subjective vitality; Ryan \& Frederick 1997) at Time 1 and the same well-being measure one year later. Then, creating the same three groups as in Study 1, the authors sought to determine whether harmonious and obsessive passion would lead to predictable changes in well-being in each group over the one-year period. The results revealed that people who were harmoniously passionate for a given activity experienced a significant increase in psychological well-being over the period, thereby replicating past findings. However, of great interest regarding the question posed above, both obsessively-passionate and non-passionate individuals experienced a slight, but significant, decrease in psychological well-being over time. Thus, overall, it

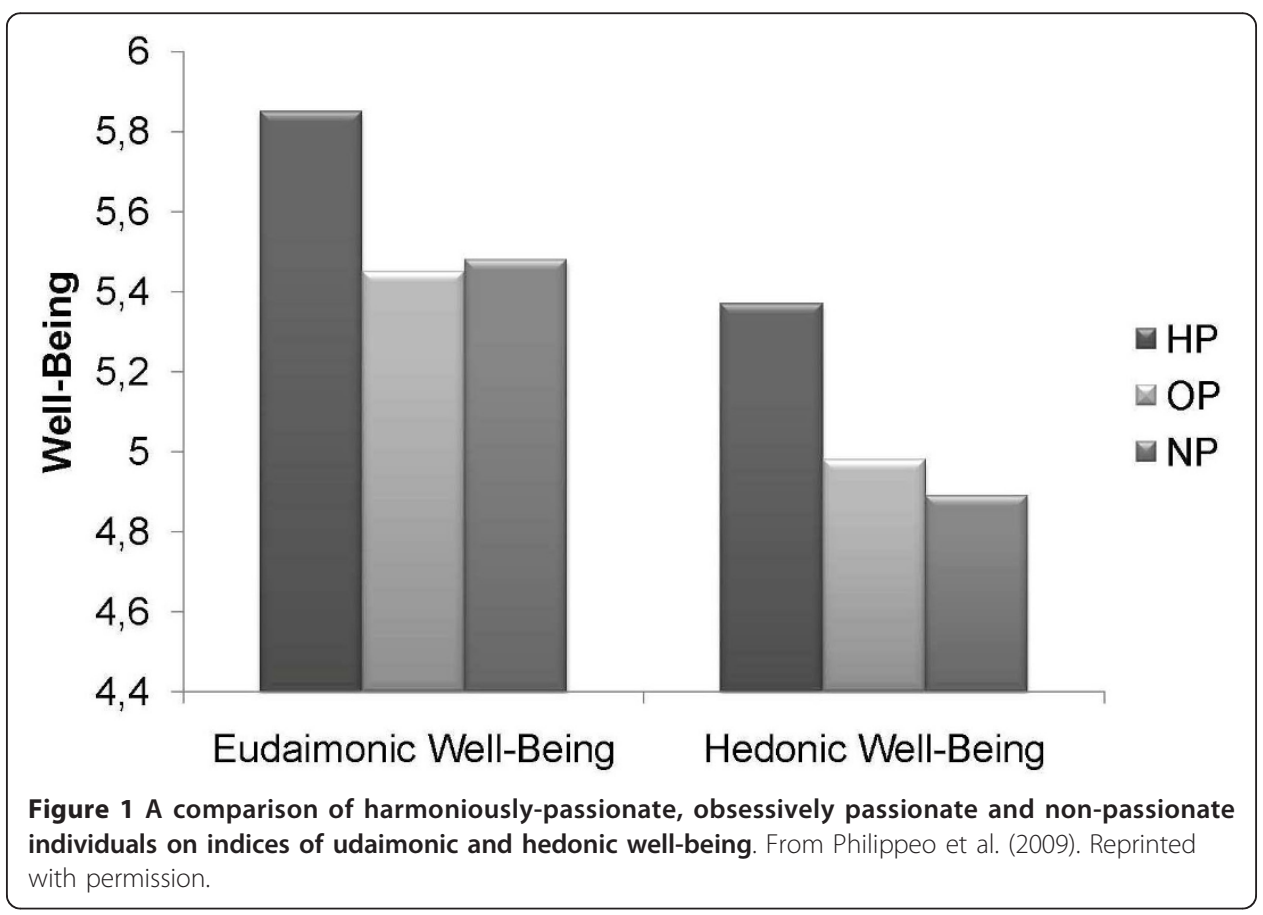


would appear that harmonious passion promotes, while obsessive passion and being non passionate, seem to undermine psychological well-being.

The research discussed so far in this section has started to assess the role of passion in promoting and protecting psychological well-being. However such research has not looked at situations wherein such functions may operate. Although goal attainment or success conditions may facilitate well-being in most people (e.g., Sheldon et al. 2002), it is following failure that the major difference between the two types of passionate individuals should take place. Because so much is riding on doing well for obsessivelypassionate individuals (e.g., maintaining their identity and their sense of self-esteem), failure may have a more devastating psychological impact on their well-being than for those who are harmoniously-passionate and who have a secure sense of self allowing them to face the negative information head on, in a mindful and non-defensive manner. Thus, whereas harmonious passion protects people's well-being in failure situations, such should not be the case for obsessive passion.

We recently tested these hypotheses in two studies (Lafrenière in press). In the first study, 64 professional painters who had more than 20 years of experience in painting participated in a web survey. They first completed the Passion Scale with respect to painting and were then randomly assigned to one of two conditions. In these conditions, they were asked to recollect either a period of their professional life when they were highly creative (success condition) or not very creative (failure condition). Then, participants were asked to recall how satisfied they were with their life at that point in time using the French form (Blais et al. 1989) of the Satisfaction with Life Scale (Diener et al. 1985). Results from regression analyses revealed the presence of a significant interaction. As hypothesized, when people were successful, both types of passion led to equally high levels of life satisfaction. However, when unsuccessful (in the failure condition), obsessive passion led to a highly significant reduction in life satisfaction. Such was not the case for harmonious passion where no significant drop in psychological well-being took place.

The above findings suggest that harmonious (but not obsessive) passion may protect psychological well-being following an important failure related to the passionate activity. However, this first study had one important limitation: it relied on participants' recollection of their life satisfaction. Thus, it is possible that memory biases explain the results (Sedikides \& Green 2000). A second study (Lafrenière et al. in press, Study 2) was thus conducted with 77 passionate hockey fans using a diary study during the 2009 National Hockey League (NHL) playoffs. Passionate fans of various hockey teams first completed the Passion Scale and the Life Satisfaction Scale through a web survey before the start of a playoffs series involving their favorite team. They then completed the Satisfaction with Life Scale each morning following their team's game which was played the night before (whether it was a loss or a win). Hierarchical linear modeling analyses were conducted on the life satisfaction data. The results replicated those of Study 1. Specifically, whereas obsessive passion accentuated the negative impact of a loss on their life satisfaction, such was not the case for harmonious passion. These findings reveal that harmonious passion does seem to play a protective function against negative events and potential drops in psychological well-being while obsessive passion seems to exacerbate such effects. 
The findings reported in this section lead to some important conclusions: First, harmonious passion would appear to positively contribute to psychological well-being and to protect against psychological ill-being. Second, obsessive passion would appear to predict psychological ill-being while being either negatively or unrelated to psychological well-being. Third, it appears that being non passionate leads to a small decrease in psychological well-being. Thus, it appears that the same (intentional) activity may or may not contribute to one's psychological well-being depending on the quality of one's engagement in the activity. Because it entails an optimal form of activity engagement, harmonious passion predicts positive well-being, while obsessive passion and its less adaptive form of defensive engagement does not. Finally, research reveals that these findings apply to men and women across the life span and on both hedonic and eudaimonic measures of psychological well-being.

What Are the Mediating Processes of the Passion-Psychological Well-Being Relationship? If passion affects psychological well-being and ill-being, then what are the processes mediating such effects? In other words, how do harmonious and obsessive passion affect psychological well-being? As indicated previously, the DMP posits that these two types of passion orient the person to engage in the activity in different fashions leading to different affective experiences that if experienced on a repeated basis can facilitate different effects on psychological well-being and ill-being. With harmonious passion, engagement is made in such a way that one engages in the activity with an openness to experience the event in a mindful non defensive manner (Brown et al. 2007; Hodgins \& Knee 2002). Such a state allows the person to derive positive affect from positive events without dwelling on the negative outcomes and its potential negative effects on one's self and well-being. Thus, harmonious passion leads to the experience of positive affect and protects against negative affect (see Philippe et al. 2010; Vallerand 2010). Because passionate activities are generally engaged in several hours each week over years, such emotional states are experienced in a repeated, on-going, fashion and thus are sustained over time (Mageau \& Miquelon 2007; Vallerand et al. 2003, Study 2). In line with Fredrickson and colleagues (Garland et al. 2010), it is hypothesized that sustained positive affective states create a positive upward spiral where attentional broadening, positive reappraisal of events, and increased thought repertoire all contribute to each other thereby promoting psychological well-being. Furthermore because they prevent the occurrence of negative emotional states, positive emotions also protect against the downward spirals of psychological ill-being.

On the other hand, with obsessive passion engagement is more defensive and rigid, preventing one from fully experiencing positive affect and orienting one to mainly experience negative affect (stress, anxiety). Furthermore, because engagement is often perceived as outside of one's control, one may therefore engage in the activity when one should not. Consequently, some negative affect such as guilt and shame may be experienced following task engagement. Finally, because of the high levels of rigidity involved in obsessive passion, not being able to engage in the passionate activity may lead a person to experience some negative affective outcomes (e.g., frustration) when engaged in other life activities. Thus, even if some positive affect were to be experienced with obsessive passion, the overall emotional state both during and after activity engagement as well as when prevented from engaging in the passionate activity may be 
quite negative (Vallerand et al. 2003, Study 1). Because the passionate activity is typically engaged in for several hours each week, such negative emotional and conflicted states are sustained over time and depending on their intensity may prevent the experience of the upward spiral of psychological well-being depicted above or worse, set in motion a downward spiral of ill-being characterized by stress appraisal, attentional narrowing, further experiences of negative emotions, and eventually psychological illbeing.

Research provides support for the proposed processes of the above model. First, research supports the adaptive role of positive affect in a variety of outcomes, including well-being (Lyubomorsky et al. 2005; Sedikides et al. 2008). In one important line of research, Fredrickson (2001), has proposed and found support for her Broaden-andBuild Theory positing that positive emotions are adaptive because they broaden people's thought-action repertoires and self, leading to better decisions and higher levels of psychological well-being. For instance, Fredrickson and Joiner (2002) uncovered the existence of a spiral where positive affect leads to higher levels of psychological wellbeing which then leads to subsequent experiences of positive affect and so on. Additional research suggests that repeated experiences of positive affect lead to changes in brain areas known to be associated with psychological well-being (see Garland et al. 2010 on this issue).

Furthermore, research on passion has systematically found that regularly engaging in a meaningful activity out of harmonious passion leads to the experience of positive affect and the protection against negative affect, while obsessive passion leads to negative affect and is either unrelated or weakly related to positive affect during task engagement (e.g., Philippe et al. 2010; Vallerand et al. 2003, Study 1; Vallerand et al. 2006, Studies 2 and 3). In addition, a 2 week-diary study (Mageau \& Vallerand 2007) revealed that the positive affect that is experienced during task engagement energized by harmonious passion is still experienced at the end of the day. Conversely, when engagement in the passionate activity is fueled by obsessive passion, not being able to engage in the passionate activity on a given day leads to feeling less positive at the end of that day. Finally, Vallerand et al. (2003, Study 2) even found that football players with a harmonious passion experienced increases in general positive affect over the course of the season while those who had an obsessive passion experienced an increase in negative affect over time.

In sum, taking into consideration the fact that harmonious passion leads to regular engagement in the passionate activity that translates into positive affect during activity engagement (e.g., Mageau et al. 2005; Vallerand et al. 2003, Study 1; Vallerand et al. 2006, Studies 2 and 3), that such positive affect seems to endure for a substantial period of time (Mageau \& Vallerand 2007; Vallerand et al. 2003, Study 2), and that positive affect positively predicts psychological well-being (Fredrickson 2001; Fredrickson et al. 2008), it would appear that having a harmonious passion can lead people to experience cumulative experiences of positive affect that should facilitate and sustain psychological well-being as well as protect against psychological ill-being. Thus, harmonious passion is expected to play a dual role of leading people to engage in the passionate activity on a regular basis and to do so in a way as to derive important emotional benefits from one's engagement that foster psychological well-being. 
However, such should not be the case for obsessive passion as it mainly promotes negative affect and psychological ill-being.

Research by Rousseau and Vallerand (2008) has tested the above model within the confines of the same study. Specifically, these authors tested the mediating role of positive and negative affect in the passion-psychological well-being relationship with senior individuals who had a passion for physical activity. At Time 1, participants completed the Passion Scale with respect to physical activity, as well as a measure of psychological well-being (life satisfaction). Five weeks later, at Time 2, immediately following an exercise session, they completed situational measures of positive and negative affect experienced while exercising (e.g., feeling happy, joyful). Finally, three weeks later, at Time 3, participants completed measures of psychological well-being again. Results from a path analysis using structural equation modeling revealed that harmonious passion positively predicted positive affect that led to increases in psychological well-being from Time 1 to Time 3. On the other hand, obsessive passion was unrelated to positive affect but positively predicted negative affect. While obsessive passion directly and negatively predicted decreases in psychological well-being, negative affect was unrelated to psychological well-being. These results are illustrated in Figure 2. These basic findings have been replicated in the work domain (Houlfort et al. 2011, Study 3) where it was found that one's harmonious passion for work led to positive affective experiences at work that in turn predicted increases in psychological well-being over a 6-month period. As in the Rousseau and Vallerand (2008) study, the negative relation between obsessive passion and well-being was direct and was not mediated by positive affect.

The above research provides support for the role of harmonious passion in leading to positive affect and the role of the latter in promoting increases in psychological wellbeing. However, such research does not address the second role of harmonious passion, namely the protective role these mediating processes may play in psychological ill-being. If harmonious passion protects ones from experiencing psychological ill-

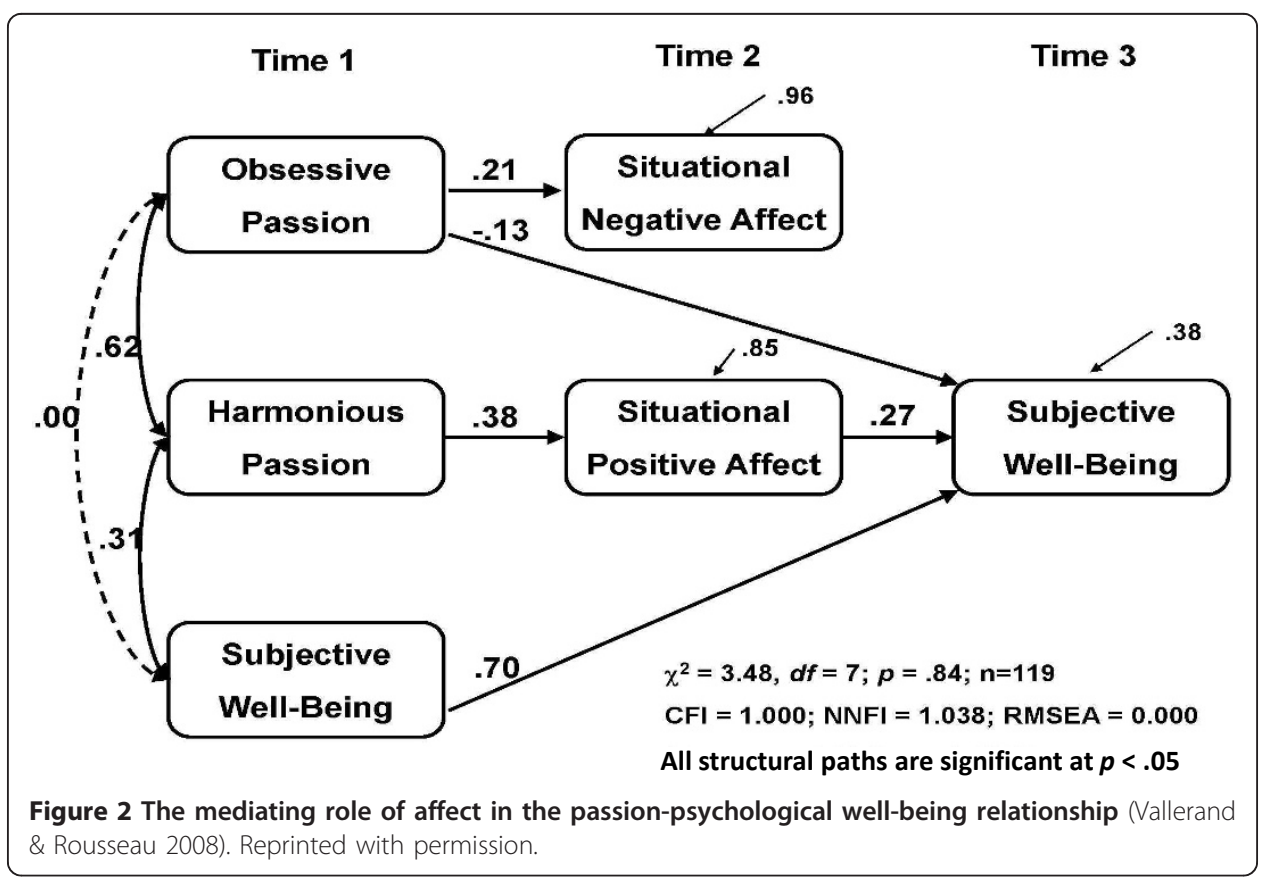


being, then are positive emotions the mediating processes involved in the process? Furthermore, the above research also showed that although obsessive passion was negatively related to psychological well-being, neither situational positive nor situational negative affect mediated the obsessive passion-psychological well-being relationship. So, what are those processes mediating the negative effects of obsessive passion on psychological ill-being?

Research addressing these two goals has focused on one type of psychological illbeing, namely burnout. In line with past research on passion and affective experiences, it was felt that harmonious (but not obsessive) passion should be conducive to the affective experience of work satisfaction that should play a protective role in burnout. With respect to obsessive passion, one likely mediator of its contributory effect should be the psychological conflict experienced between the passionate activity (work) and other life activities (e.g., family activities).

Because with obsessive passion one experiences an uncontrollable urge to engage in the passionate activity, it becomes very difficult for the person to fully disengage from thoughts about the activity (or from engaging in the activity altogether), leading to conflict with other activities in the person's life. Such conflict can prevent the person from engaging in other life pursuits. The person thus remains mentally stale which may contribute to burnout (Garland et al. 2010). In addition, because obsessive passion is typically unrelated to positive affective experiences both during task engagement in the passionate activity (work) and in other life pursuits outside of it, obsessive passion does not trigger the protective function against ill-being like harmonious passion does. Conversely, with harmonious passion, the person can let go of the passionate activity after task engagement and fully immerse in other life pursuits without experiencing conflict between the two. Thus, harmonious passion should allow the person to experience affective rewards both during task engagement in the passionate activity as well as in other life pursuits, thereby protecting the person against burnout.

In line with the above reasoning, two studies (Vallerand et al. 2010, Studies 1 and 2) were conducted with professional nurses from two cultures (France and Quebec, Canada). In Study 1, 100 nurses from France completed scales assessing passion for their work, psychological conflict, work satisfaction, and burnout. The results from structural equation modeling analyses are displayed in Figure 3. It can be seen that the model was supported, even when controlling for the weekly number of hours worked. Specifically, obsessive passion facilitated the experience of burnout through the psychological conflict it induces between work and other life activities. There was also an absence of relationship between obsessive passion and work satisfaction. On the other hand, harmonious passion prevented the experience of conflict and contributed to the experience of work satisfaction, thereby protecting the person from experiencing burnout. These findings were replicated in a second study using a prospective design with nurses from the Province of Quebec (Vallerand et al. 2010, Study 2), allowing us to predict changes in burnout over a six-month period. Thus, although additional research is clearly needed, it would appear that harmonious passion can serve protective functions against psychological ill-being. Conversely, obsessive passion seems to contribute to ill-being through the conflict it creates between the passionate activity (work) and other life activities that may help the person to replenish themselves. 


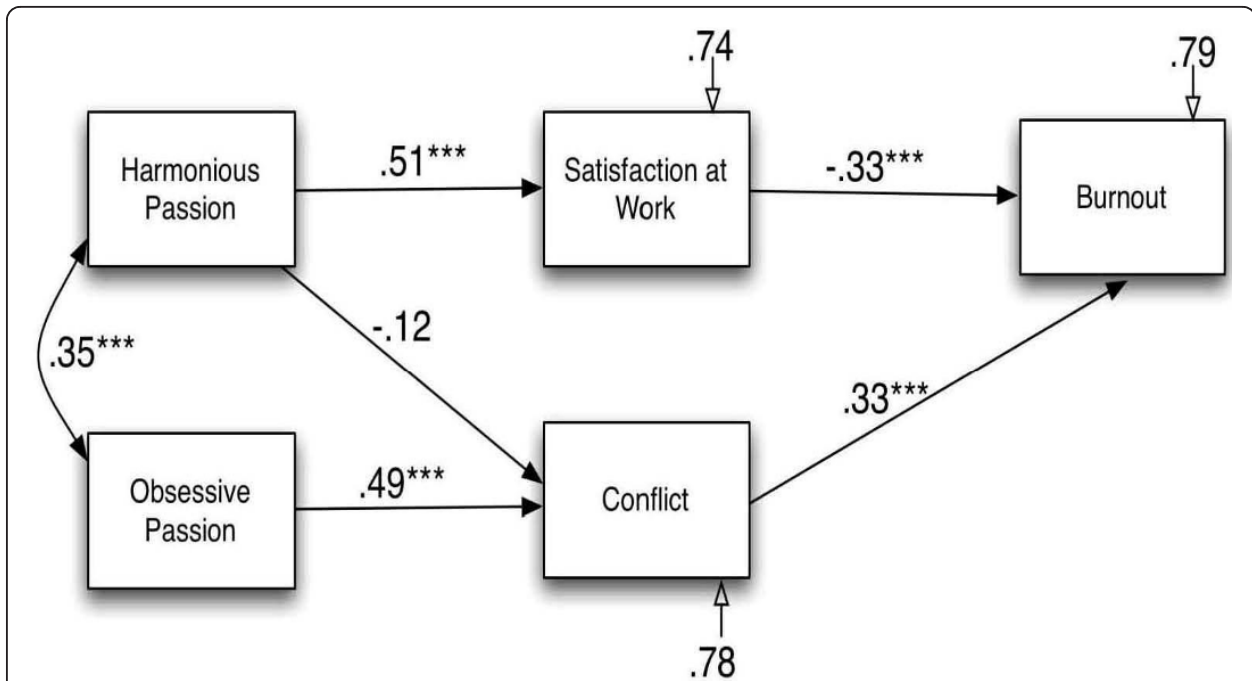

Figure 3 The role of passion in burnout (Vallerand et al. 2010, Study 1). Reprinted with permission. All paths are significant at $p<.05$ except for the Harmonious Passion-Conflict path, $p<.10$.

Two caveats are in order. First, one may suggest that some personality or individual differences underlies the distinction between the two types of passion and is responsible for the various effects of passion on well-being. While this is possible, recent unpublished research from two different labs (Balon et al. 2010; Vallerand et al. 2012) shows that the two types of passion are only weakly related to some of the Big 5 personality dimensions and unrelated to the others. Thus, it would appear unlikely that personality is responsible for the observed effects with passion. A second caveat is that research conducted on passion and outcomes has been largely correlational in nature. Thus, the issue of causality needs attention. One study has attempted to shed some light on this issue. In this study (Carbonneau et al. 2008), a cross-lagged panel design was used where 500 teachers were asked to complete measures of passion toward teaching as well as measures of psychological measures of well-being (work satisfaction) and ill-being (burnout) twice over a 3-month period. Results of a cross-lagged path model with structural equation modeling revealed that passion predicted changes in outcomes whereas outcomes did not predict changes in passion. Passion, then, would appear to be involved in producing changes in psychological outcomes, whereas the reverse may not be true. Clearly, additional research using an experimental design is necessary before one can firmly conclude that passion causes outcomes. However, results from the Carbonneau et al. (2008) study suggest that this may be the case.

\section{Beyond Mere Engagement In Intentional Activities}

It might be informative to return to the issue of intentional activities. One question we may pose is the following: Is mere engagement in intentional activities sufficient to positively affect psychological well-being? While I agree that some activities may be more positive than others in bringing about positive affective experiences and psychological well-being, such as mindfulness meditation (Lutz et al. 2008) and loving-kindness meditation (Fredrickson et al. 2008), the main message of this paper is that the activity is not the whole story, far from it. What also (and perhaps mainly) matters is how people engage in a given activity. In addition to helping the person return to the 
activity on a regular basis, one's passion also determines the quality of engagement in the activity. Thus, to the extent that one's passion for a given activity is harmonious, then one should be able to reap full benefits from engagement in a "positive" activity such as meditation. However, if one's passion is obsessive, then less than optimal, and perhaps even negative, outcomes should be experienced.

We have recently tested these hypotheses with an activity widely recognized as highly positive, namely Yoga. Yoga is a discipline that originates from India and that focuses on the development and maintenance of the natural balance between mind, body, and soul. Research reveals that the yoga practice can enhance muscular strength and body flexibility, promote respiratory and cardiovascular function, increase positive affect and decrease negative affect (Impett et al. 2006), as well as enhance psychological wellbeing (Collins 1998). If only the activity matters, then passion for Yoga should not make a difference and mere engagement in Yoga should be enough to derive some positive consequences. However, if passion does matter, then even with Yoga, only harmonious passion should lead to positive benefits while obsessive passion may be unrelated to outcomes or may even lead to some negative effects.

Two studies were conducted (Carbonneau et al. 2010, Studies 1 and 2). In the first study, participants from the "normal population" (ranging in age from 19 to 60 years) who had been engaging in Yoga for several years completed the Passion Scale for Yoga as well as scales assessing positive and negative affect and state anxiety experienced during Yoga classes. Results revealed that only harmonious passion was positively associated with positive affect and negatively with negative affect and state anxiety. Obsessive passion was only positively associated (but non significantly so) with state anxiety. Study 2 went further and looked at changes in outcomes that took place over a 3month period for regular Yoga participants once more from the normal population. Results basically replicated those of Study 1. Specifically, harmonious passion predicted decreases in negative emotions, state anxiety, and general (negative) physical symptoms, but increases in positive emotions that took place over time during Yoga classes. Obsessive passion only predicted a significant increase in negative emotions experienced during Yoga classes. These findings were obtained even while controlling for the number of weekly hours and years of involvement in Yoga.

These findings are important for at least two reasons. First, they underscore the fact that we need to go beyond mere engagement in intentional activities even as positive as Yoga to determine the type of affective experiences that will be experienced by the person. The quality of activity engagement matters, with harmonious passion leading to a more positive engagement and consequently to more positive (and less negative) outcomes than obsessive passion. Second, if "positive" activities such as Yoga do not automatically lead to positive affective experiences during activity engagement, then their positive effects on psychological well-being are not automatic either. It would thus appear that harmonious passion should play a key role in the positive effect of involvement in activities even as positive as Yoga in psychological well-being. However, because psychological well-being measures were not assessed in the Carbonneau et al. (2010) studies, future research is needed in order to more directly test this hypothesis.

A final point as pertains to the role of the activity in the psychological outcomes experienced relates to what may be called "negative" activities. Specifically, if harmonious passion promotes the quality of one's affective experiences during engagement in 
a "positive" activity, can it also protect the person when engaging in a more "negative" type of activity? While it is difficult to identify a clearly negative activity, gambling may come close to it. Indeed, much research reveals that gambling (and certain types of gambling activities in particular such as video poker machines) may be particularly negative for the person, leading to pathological gambling, social isolation, depression, and even suicide (Bergh \& Kühlhorn 1994). As such, if harmonious passion serves protective functions, then engaging in gambling out of harmonious passion should protect one from experiencing negative affect and developing pathological gambling. However, this should not be the case for obsessive passion. In fact, obsessive passion would be expected to even contribute to both.

Research supports the above hypotheses. Indeed, harmonious passion for gambling has typically been found to be positively related mainly to positive affective experiences while gambling such as pleasure, fun, and enjoyment (see Mageau et al. 2005) and to be unrelated or even negatively related to pathological gambling (Philippe \& Vallerand 2007; Ratelle et al. 2004; Skitch \& Hodgins 2005; Vallerand et al. 2003, Study 4). Conversely, research has shown that obsessive passion for gambling is positively associated with negative emotions such as anxiety and guilt when playing as well as with rumination when prevented from gambling. Obsessive passion is also positively related to pathological gambling (Philippe \& Vallerand 2007; Ratelle et al. 2004; Skitch \& Hodgins 2005; Vallerand et al. 2003, Study 4).

The above findings on the role of passion in gambling underscore the fact that the activity by itself does not explain all effects on psychological ill-being and that one's passion for it matters. It would appear that while harmonious passion may prevent the experience of negative affect and psychological problems such as pathological gambling when engaging in a potentially problematic activity such as gambling, obsessive passion would appear to contribute to such negative experiences. However, a more systematic analysis of activity type (positive vs negative features) and passion types is needed in order to more firmly determine the role of each in psychological well and ill-being.

\section{Conclusions}

In the present paper, the role of passion for activities in sustainable psychological wellbeing was detailed. The DMP proposes the existence of two types of passion: harmonious and obsessive, which can be differentiated in terms of how the representation of the passionate activity has been internalized into one's identity. Harmonious passion originates from an autonomous internalization of the activity into one's identity and promotes a mindful and open form of activity engagement. Such engagement is hypothesized to lead to repeated positive affective experiences in the activity that spills over in one's life in general that, in turn, facilitates sustainable psychological well-being while preventing the experience of negative affect, psychological conflict, and ill-being. Conversely, obsessive passion emanates from a controlled internalization and is hypothesized to minimize the experience of positive affect and psychological well-being and to even facilitate negative affect, conflict with other life activities, and psychological ill-being. Research supporting the above hypotheses was presented.

At least three broad directions for future directions can be proposed. The first deals with the relative effects of different types of affective experiences in psychological wellbeing and the role of passion in these. Specifically, do different types of positive 
emotions (e.g., joy, pride, excitement) have the same impact on psychological wellbeing? Do other positive experiences such as flow also contribute to psychological well-being? Which one contributes the most (i.e., positive affect vs flow)? What is the role of passion in these various affective states? A second research direction that would appear important deals with the role of affective adaptation in psychological well-being. Research on affective adaptation (see Wilson \& Gilbert 2008) has shown that certain factors (e.g., uncertainty) can ensure that positive affect is maintained longer. An interesting question becomes "Does positive affect longevity contributes to psychological well-being on top of positive affect intensity and frequency". And if so, what is the role of harmonious passion in facilitating such sustained positive affectivity? Finally, a last research avenue pertains to the determinants of passion. Such research should attempt to identify the "best practices" or ways to facilitate the development of a harmonious passion (and prevent an obsessive passion) for a given activity, thereby leading to the experience of positive affect and, in turn, sustainable psychological well-being. Past research on the development of passion (Mageau et al. 2009) has shown that providing autonomy support (or choice) regarding which activity to choose as well as when and how to engage in it should be conducive to a harmonious passion for an activity to the extent that the latter is valued by the person and is consonant with aspects of the person's identity. Research is needed in order to package these elements so that people can readily develop a harmonious passion and gain well-being benefits from activity engagement.

In sum, the take home message from this paper is that being passionate toward a given activity will lead the person to engage in the activity frequently, often over several years and sometimes a lifetime. Harmonious passion for a given activity will generally lead to the experience of positive emotions during activity engagement. Such emotions, in turn, will foster increases in psychological well-being. Thus, over time, harmonious passion is expected to facilitate sustainable increases in psychological wellbeing and prevent against ill-being. Obsessive passion, while ensuring regular activity engagement, does not produce such psychological gains and may even facilitate some deleterious effects. Clearly, not all intentional activities produce positive effects on psychological well-being. In this light, harmonious passion would deserve much attention as a major contributor of sustainable psychological well-being. Future research on some of the issues raised above would therefore appear rather promising.

\section{Author Note}

Robert J. Vallerand, Laboratoire de Recherche sur le Comportement Social, Université du Québec, Montréal, Québec, Canada. This research program was supported by grants from the Fonds Québécois pour la Recherche sur la Société et la Culture (FQRSC) and the Social Sciences Humanities Research Council of Canada (SSHRC). Correspondence concerning this article should be addressed to Robert J. Vallerand, Laboratoire de Recherche sur le Comportement Social, Département de psychologie, Université du Québec à Montréal, C.P. 8888, succursale Centre-ville, Montréal, Québec, Canada, H3C 3P8. Electronic mail may be sent to Vallerand.bob@gmail.com. Additional information on this program of research can be obtained by visiting the following website http://www.psycho.uqam.ca/lrcs 


\section{Competing interests}

The author declares that they have no competing interests.

Received: 31 May 2011 Accepted: 21 March 2012 Published: 21 March 2012

\section{References}

Algoe SB, Haidt J, Gable SL (2008). Beyond reciprocity: Gratitude and relationships in everyday life. Emotion, 8, 424-429.

Aron A, Aron EN, Smollan D (1992). Inclusion of other in the self scale and the structure of interpersonal closeness. Journal of Personality and Social Psychology, 63, 596-612.

Balon S, Lecoq J, Rimé B: Passion and personality. Paper presented at the International Congress of differential psychology, Marseilles, France, August 272010.

Baum JR, Locke EA (2004). The relationship of entrepreneurial traits, skill, and motivation to subsequent venture growth. Journal of Applied Psychology, 89, 587-598.

Bergh C, Kühlhorn E (1994). Social, psychological, and physical consequences of pathological gambling in Sweden. Journal of Gambling Studies, 10, 275-285.

Blais MR, Vallerand RJ, Pelletier LG, Brière NM (1989). L'échelle de satisfaction de vie: Validation canadienne-française du "Satisfaction With Life Scale" [French-Canadian Validation of the Satisfaction With Life Scale]. Canadian Journal of Behavioural Sciences, 21, 210-223.

Brickman P, Campbell DT: Hedonic relativism and planning the good society. In Adaptation-level theory. Edited by: Appley MH. New York: Academic Press; 1971:287-302.

Brown KW, Ryan RM, Creswell JD (2007). Mindfulness: Theoretical foundations and evidence for its salutary effects. Psychological Inquiry, 18, 211-237.

Carbonneau N, Vallerand RJ, Fernet C, Guay F (2008). The role of passion for teaching in intra and interpersonal outcomes. Journal of Educational Psychology, 100, 977-988.

Carbonneau N, Vallerand RJ, Massicotte S (2010). Is the practice of Yoga associated with positive outcomes? The role of passion. The Journal of Positive Psychology, 5, 452-465.

Castelda BA, Mattson RE, MacKillop JE, Anderson EJ, Burright R, Donovick PJ (2007). Psychometric validation of the gambling passion scale (GPS). International Gambling Studies, 7, 173-182.

Collins C(1998). Yoga: Intuition, preventive medicine, and treatment. Journal of Obstetric, Gynecologic, and Neonatal Nursing, 27, 563-568.

Csikszentmihalyi M, Rathunde K, Whalen S: Talented teenagers: The roots of success and failure New York: Cambridge; 1993.

Deci EL, Eghrari H, Patrick BC, Leone DR (1994). Facilitating internalization: The self-determination perspective. Journal of Personality, 62, 119-142.

Deci EL, Ryan RM (2000). The "what" and "why" of goal pursuits: Human needs and the self-determination of behavior Psychological Inquiry, 11, 227-268.

Diener E (2000). Subjective well-Being: The Science of Happiness and a Proposal for a National Index. American Psychologist, $55,34-43$

Diener E, Emmons RA, Larsen RJ, Griffin S (1985). The Satisfaction With Life Scale. Journal of Personality Assessment, 49, 71-76.

Fredrickson BL (2001). The role of positive emotions in positive psychology: The Broaden-and Build theory of positive emotions. American Psychologist, 56, 218-226.

Fredrickson BL, Cohn MA, Coffey KA, Pek J, Finkel SM (2008). Open hearts build lives: Positive emotions, induced through loving-kindness meditation, build consequential personal resources. Journal of Personality and Social Psychology, 95, 1045-1062.

Fredrickson BL, Joiner T (2002). Positive emotions trigger upward spirals toward emotional well-being. Psychological Science, $13,172-175$

Frijda NH, Mesquita B, Sonnemans J, Van Goozen S: The duration of affective phenomena or emotions, sentiments and passions. In International review of studies on emotion. Volume 1. Edited by: Strongman KT. New York: Wiley; 1991:187-225.

Froh JJ, Sefick WJ, Emmons RA (2008). Counting blessings in early adolescents: An experimental study of gratitude and subjective well-being. Journal of School Psychology, 46, 213-233.

Gable SL, Haidt J (2005). What (and why) is positive psychology? Review of General Psychology, 9, 103-110.

Garland EL, Fredrickson B, Kring A, Johnson DP, Meyer PS, Penn DL: Upward spirals of positive emotions counter downwoard spirals of negativity: Insights from the Broaden-and-Build theory and affective neurosicnece on the treatment of emotion dysfunctions and deficits in psychopathology. Clinical Psychology Review 2010.

Goldberg DP, Hillier VF (1979). A scaled version of the General Health Questionnaire. Psychological Medicine, 9, 139-145.

Hatfield E, Walster GW: A new look at love Reading, MA: Addison-Wesley; 1978

Hodgins HS, Knee R: The integrating self and conscious experience.Edited by: Deci EL, Ryan RM. Rochester, NY: University of Rochester Press; 2002:87-100.

Houlfort N, Vallerand RJ, Forest J, Lavigne GL, Koestner R: On the role of passion for work in psychological well-being. Paper submitted for publication 2011.

Huppert FA (2009). Psychological well-being: Evidence regarding its causes and consequences. Applied Psychology: Health and Well-Being, 1, 137-164.

Impett EA, Daubenmier JJ, Hirschman AL (2006). Minding the body: Yoga, mbodiment, and well-being. Sexuality Research \& Social Policy: A Journal of the NSRC, 3, 39-48.

Keyes CLM (2007). Promoting and protecting mental health as flourishing: A complementary strategy for improving national mental health. American Psychologist, 62, 95-108.

King LA (2001). The health benefits of writing about life goals. Personality and Social Psychology Bulletin, 27, 798-807.

Lafrenière M-AK, St-Louis A, Vallerand RJ: The role of passion and success/failure experiences in life satisfaction. Self and Identity .

Lutz A, Slagter HA, Dunne JD, Davidson RJ (2008). Attention regulation and monitoring in meditation. Trends in Cognitive Science, 12, 163-169.

Lykken D, Tellegen A (1996). Happiness is a stochastic phenomenon. Psychological Science, 7, 186-189. 
Lyubomirsky S, King L, Diener E (2005). The benefits of frequent positive affect: Does happiness lead to success? Psychological Bulletin, 131, 803-855.

Lyubomirsky S, Sheldon KM, Schkade D (2005). Pursuing happiness: The architecture of sustainable change. Review of General Psychology, 9, 111-131.

Mageau G, Carpentier J, Vallerand RJ: The role of self-esteem contingencies in the distinction between obsessive and harmonious passion. European Journal of Social Psychology.

Mageau G, Vallerand RJ (2007). The moderating effect of passion on the relation between activity engagement and positive affect. Motivation and Emotion, 31, 312-321.

Mageau GA, Vallerand RJ, Charest J, Salvy S-J, Lacaille N, Bouffard T, Koestner R (2009). On the development of harmonious and obsessive passion: The role of autonomy support, activity valuation, and identity processes. Journal of Personality, 77, 601-645.

Mageau GA, Vallerand RJ, Rousseau FL, Ratelle CF, Provencher PJ (2005). Passion and gambling: Investigating the divergent affective and cognitive consequences of gambling. Journal of Applied Social Psychology, 35, 100-118.

Miquelon P, Vallerand RJ (2006). Goal motives, well-being, and physical health: Happiness and self realization as psychological resources under challenge. Motivation \& Emotion, 30, 259-272.

Philippe F, Vallerand RJ (2007). Prevalence rates of gambling problems in Montreal, Canada: A look at old adults and the role of passion. Journal of Gambling Studies, 23, 275-283.

Philippe FL, Vallerand RJ, Houlfort N, Lavigne G, Donahue EG (2010). Passion for an activity and quality of interpersonal relationships: The mediating role of positive and negative emotions. Journal of Personality and Social Psychology, 98, 917-932.

Philippe F, Vallerand RJ, Lavigne G (2009). Passion does make a difference in people's lives: A look at well-being in passionate and non-passionate individuals. Applied Psychology: Health and Well-Being, 1, 3-22.

Ratelle CF, Vallerand RJ, Mageau GA, Rousseau FL, Provencher P (2004). When passion leads to problematic outcomes: A look at gambling. Journal of Gambling Studies, 20, 105-119.

Rony J-A: Les passions (The passions) Paris: Presses universitaires de France; 1990.

Rousseau FL, Vallerand RJ (2003). Le rôle de la passion dans le bien-être subjectif des aînés TThe role of passion in the subjective well-being of the elderly]. Revue Québécoise de Psychologie, 24, 197-211.

Rousseau FL, Vallerand RJ (2008). An examination of the relationship between passion and subjective well-being in older adults. International Journal of Aging and Human Development, 66, 195-211.

Rousseau FL, Vallerand RJ, Ratelle CF, Mageau GA, Provencher PJ (2002). Passion and gambling: On the validation of the Gambling Passion Scale (GPS). Journal of Gambling Studies, 18, 45-66.

Ryan RM, Deci EL (2003): On assimilating identities of the self: A Self-Determination Theory perspective on internalization and integrity within cultures. In Handbook of self and identity. Edited by: Leary MR, JP Tangney. New York: Guilford; 2003:253-272.

Ryan RM, Frederick C (1997). On energy, personality, and health: Subjective vitality as a dynamic reflection of well-being. Journal of Personality, 65, 529-565.

Ryff CD, Keyes CL (1995). The structure of psychological well-being revisited. Journal of Personality and Social Psychology, 69, 719-727.

Sedikides C, Green JD (2000). On the self-protective nature of inconsistency/negativity management: Using the person memory paradigm to examine self-referent memory. Journal of Personality and Social Psychology, 79, 906-922.

Sedikides C, Wildschut T, Arndt J, Routledge C (2008). Nostalgia: Past, present, and future. Current Directions in Psychological Science, 17, 304-307.

Seligman MEP: Flourish: A visionary new understanding of happiness and well-being New York: Simon \& Schuster; 2011.

Skitch SA, Hodgins DC (2005). A passion for the game: Problem gambling and passion among university students. Canadian Journal of Behavioral Science, 37, 193-197.

Sheldon KM: The Self-Concordance Model of healthy goal-striving: When personal goals correctly represent the person. In Handbook of self-determination research. Edited by: Deci EL, Ryan RM. Rochester, NY: The University of Rochester Press; 2002:65-86.

Sheldon KS, Kasser T, Smith K, Share T (2002). Personal goals and psychological growth: Testing an intervention to enhance goal-attainment and personality integration. Journal of Personality, 70, 5-31.

Steger MF, Frazier P, Oishi S, Kaler M (2006). The Meaning in Life Questionnaire: Assessing the presence of and search for meaning in life. Journal of Counseling Psychology, 53, 80-93.

Vallerand RJ (2008). On the psychology of passion: In search of what makes people's lives most worth living. Canadian Psychology, 49, 1-13.

Vallerand RJ: On passion for life activities: The Dualistic Model of Passion. In Advances in experimental social psychology. Volume 42. Edited by: Zanna MP. New York: Academic Press; 2010:97-193.

Vallerand RJ, Blanchard CM, Mageau GA, Koestner R, Ratelle CF, Léonard M, et al (2003). Les passions de l'âme: On obsessive and harmonious passion. Journal of Personality and Social Psychology, 85, 756-767.

Vallerand RJ, Fortier MS, Guay F (1997). Self-determination and persistence in a real-life setting: Toward a motivational model of high school dropout. Journal of Personality and Social Psychology, 72, 1161-1176.

Vallerand RJ, Houlfort N: Passion at work: Toward a new conceptualization. In Emerging perspectives on values in organizations. Edited by: Gilliland SW, Steiner DD, Skarlicki DP. Greenwich, CT: Information Age Publishing; 2003:175-204.

Vallerand RJ, Lafrenière M-A, Philippe F: On harmonious and obsessive passion: A nomological network analysis. Manuscript in preparation 2012.

Vallerand RJ, Mageau GA, Elliot A, Dumais A, Demers M-A, Rousseau FL (2008). Passion and performance attainment in sport. Psychology of Sport \& Exercise, 9, 373-392.

Vallerand RJ, Miquelon P: Passion for sport in athletes. In Social psychology in sport. Edited by: Lavallée D, Jowett S. Champaign, IL: Human Kinetics; 2007:249-262.

Vallerand RJ, Paquet Y, Philippe FL, Charest J (2010). On the role of passion in burnout: A process model. Journal of Personality, 78, 289-312.

Vallerand RJ, Rousseau FL, Grouzet FME, Dumais A, Grenier S (2006). Passion in sport: A look at determinants and affective experiences. Journal of Sport \& Exercise Psychology, 28, 454-478. 
Vallerand RJ, Salvy SJ, Mageau GA, Elliot AJ, Denis P, Grouzet FME, Blanchard CB (2007). On the role of passion in performance. Journal of Personality, 75, 505-534

Wilson TD, Gilbert DT (2008). Explaining away: A model of affective adaptation. Perspectives on Psychological Science, 3 , 370-386.

doi:10.1186/2211-1522-2-1

Cite this article as: Vallerand: The role of passion in sustainable psychological well-being. Psychology of Well-Being: Theory, Research and Practice 2012 2:1.

Submit your manuscript to a SpringerOpen ${ }^{\circ}$ journal and benefit from:

- Convenient online submission

- Rigorous peer review

- Immediate publication on acceptance

- Open access: articles freely available online

- High visibility within the field

- Retaining the copyright to your article

Submit your next manuscript at $\gg$ springeropen.com 